\title{
Gentamicin Blocks the ACh-Induced BK Current in Guinea Pig Type II Vestibular Hair Cells by Competing with $\mathrm{Ca}^{2+}$ at the L-Type Calcium Channel
}

\author{
Hong Yu ${ }^{1, \dagger}$, Chang-Kai Guo ${ }^{1, \dagger}$, Yi Wang ${ }^{1}$, Tao Zhou ${ }^{1}$ and Wei-Jia Kong ${ }^{1,2,3, *}$
}

1 Department of Otorhinolaryngology, Union Hospital of Tongji Medical College, Hua-Zhong University of Science and Technology, 1277 Jiefang Avenue, Wuhan 430022, China; E-Mails: yuhong_0706@163.com (H.Y.); ckguo2255@sina.com (C.-K.G.); entwy821@163.com (Y.W.); entzt2013@sina.com (T.Z.)

2 Institute of Otorhinolaryngology, Union Hospital, Tongji Medical College, Hua-Zhong University of Science and Technology, 1277 Jiefang Avenue, Wuhan 430022, China

3 Key Laboratory of Neurological Disease, Ministry of Education, Tongji Medical College, Hua-Zhong University of Science and Technology, Wuhan 430022, China

$\dagger$ These authors contributed equally to this work.

* Author to whom correspondence should be addressed; E-Mail: entwjkong@hust.edu.cn; Tel.: +86-27-8572-6900; Fax: +86-27-8577-6343.

Received: 10 February 2014; in revised form: 3 March 2014 / Accepted: 9 April 2014 / Published: 22 April 2014

\begin{abstract}
Type II vestibular hair cells (VHCs II) contain big-conductance $\mathrm{Ca}^{2+}$-dependent $\mathrm{K}^{+}$channels (BK) and L-type calcium channels. Our previous studies in guinea pig VHCs II indicated that acetylcholine ( $\mathrm{ACh}$ ) evoked the $\mathrm{BK}$ current by triggering the influx of $\mathrm{Ca}^{2+}$ ions through L-type $\mathrm{Ca}^{2+}$ channels, which was mediated by M2 muscarinic ACh receptor (mAChRs). Aminoglycoside antibiotics, such as gentamicin (GM), are known to have vestibulotoxicity, including damaging effects on the efferent nerve endings on VHCs II. This study used the whole-cell patch clamp technique to determine whether GM affects the vestibular efferent system at postsynaptic M2-mAChRs or the membrane ion channels. We found that GM could block the ACh-induced BK current and that inhibition was reversible, voltage-independent, and dose-dependent with an $\mathrm{IC}_{50}$ value of $36.3 \pm 7.8 \mu \mathrm{M}$. Increasing the ACh concentration had little influence on GM blocking effect, but increasing the extracellular $\mathrm{Ca}^{2+}$ concentration $\left(\left[\mathrm{Ca}^{2+}\right]_{0}\right)$ could antagonize it. Moreover, $50 \mu \mathrm{M} \mathrm{GM}$ potently blocked $\mathrm{Ca}^{2+}$ currents activated by (-)-Bay-K8644, but did not block BK currents
\end{abstract}


induced by NS1619. These observations indicate that GM most likely blocks the M2 mAChR-mediated response by competing with $\mathrm{Ca}^{2+}$ at the L-type calcium channel. These results provide insights into the vestibulotoxicity of aminoglycoside antibiotics on mammalian VHCs II.

Keywords: gentamicin; vestibular hair cells; big conductance calcium-dependent potassium channel; acetylcholine; calcium channel

\section{Introduction}

Aminoglycoside antibiotics are commonly used in developing countries due to their powerful broad-spectrum bactericidal ability, inexpensive cost and low allergenicity. However, widespread use of aminoglycosides has been restricted because of the incidence of serious side effects, such as nephrotoxicity, ototoxicity and muscle paralysis. Moreover, intratympanic application of gentamicin (GM), an ototoxic aminoglycoside, could be efficacious for treating vertigo in Meniere's disease because it is more toxic to vestibular hair cells (VHCs) than cochlea hair cells [1-3]. Most studies have focused on the molecular mechanism of the hair cell damage by aminoglycosides. However, less electrophysiological evidence exists regarding the mechanism ofotoxicity, especially the vestibulotoxicity of aminoglycosides.

Many studies have demonstrated that aminoglycosides, including GM, can block many ion channels, such as voltage-gated calcium channels [4-7], mechanosensitive ion channels [8-12], and nicotinic ACh receptors ( $n$ AChRs) [13-15]. GM also has been shown to block the suppression effects of the medial olivocochlear efferent system in guinea pig [16-19]. It was previously reported that acute GM application can block the $\mathrm{Ca}^{2+}$ channel and the $\mathrm{Ca}^{2+}$-dependent $\mathrm{K}^{+}$channel in semicircular canal hair cells of the frog [20]. However, in mammals, it remains poorly understood whether GM could affect the vestibular efferent system and whether GM could block ion channels present on VHCs.

$\mathrm{ACh}$ is the major inhibitory neurotransmitter of the vestibular efferent system [21]. Many studies have shown that mammalian VHCs express muscarinic ACh receptor (mAChR) subtypes [11,22,23] and nAChR subunits [24-26]. Our previous studies found that ACh could activate big-conductance $\mathrm{Ca}^{2+}$-dependent $\mathrm{K}^{+}$channels (BK) mediated by M2 mAChRs and L-type calcium channels in guinea pig type II VHCs (VHCs II) [27-29]. Blanchet et al. [14] reported that GM could block the influx of $\mathrm{Ca}^{2+}$ through nAChRs in guinea pig outer hair cells. Therefore, we speculated that GM might have an effect on M2 AChRs in VHCs II and might block ion channels such as L-type $\mathrm{Ca}^{2+}$ channels and BK channels in VHCs II. The aim of this study was to determine whether GM could inhibit the vestibular efferent system at postsynaptic M2-mAChRs or the membrane ion channels such as BK channels and the L-type calcium channel in guinea pig VHCs II. 


\section{Results}

2.1. GM Reversibly Blocked the ACh-Induced BK Current in Guinea Pig VHCs II in a Dose-Dependent and Voltage-Independent Manner

The effect of GM was assessed by comparing responses of VHCs II to applications of ACh with or without GM. Both 30 and $50 \mu \mathrm{M}$ GM reversibly blocked ACh-induced BK currents in guinea pig VHCs II. Methoctramine (100 nM), an M2 selective AChR antagonist, was chosen as control (Figure 1A). The cell was washed with normal external solution after every drug application until it returned to normal. As shown in Figure 1B, 30 and $50 \mu \mathrm{M}$ GM blocked ACh $(100 \mu \mathrm{M})$-induced BK currents by $37.1 \% \pm 10.1 \%(n=6)$ and $55.0 \% \pm 7.4 \%(n=6)$, respectively, while $100 \mathrm{~nm}$ methoctramine blocked it by $66.3 \% \pm 12.4 \%(n=5)$.

Figure 1. Effect of GM on the ACh-induced BK current. (A) Both 30 and $50 \mu \mathrm{M}$ GM blocked the BK current evoked by $100 \mu \mathrm{M}$ ACh. Methoctramine $(100 \mathrm{nM})$ was used as a control. The above results were obtained from the same cell at $-50 \mathrm{mV}$; (B) Bar histogram shows the percentage of blocking effect of $30 \mu \mathrm{M}$ GM, $50 \mu \mathrm{M}$ GM and $100 \mathrm{nM}$ methoctramine on the current evoked by $100 \mu \mathrm{M}$ ACh. Each point is the mean $\pm \mathrm{SD}$ of $5-6$ cells.

A

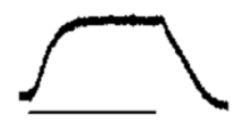

$\overline{100 \mu \mathrm{MACh}}$

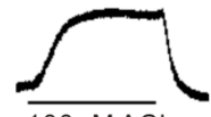

$\overline{100 \mu \mathrm{M} \mathrm{ACh}}$

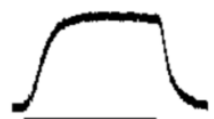

$\overline{100 \mu \mathrm{MACh}}$
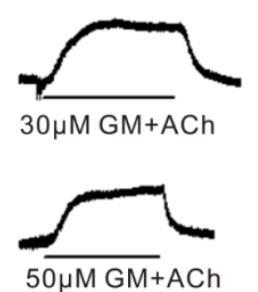

o0nM methoctramine
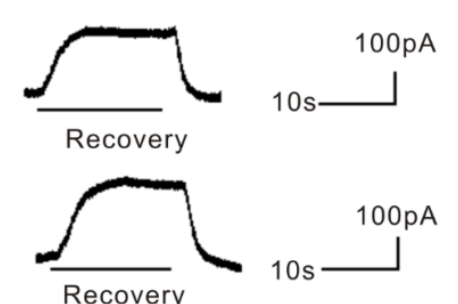

Ch

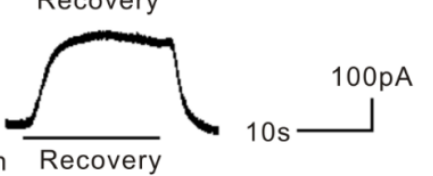

B

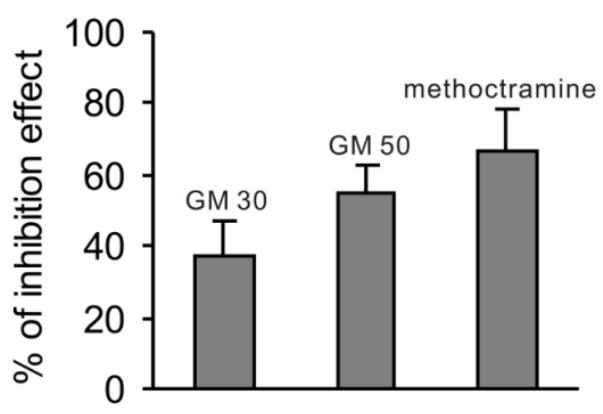

Next, the relationship between the inhibitory effect and the concentration of GM was studied. The dose dependency of the GM blocking effect was estimated by applying five different concentrations of GM, ranging from 10 to $300 \mu \mathrm{M}$, to the same VHC II (Figure 2A). The dose-inhibition curve of GM indicated that the dose for half-blocking response $\left(\mathrm{IC}_{50}\right)$ was $36.3 \pm 7.8 \mu \mathrm{M}$ with a Hill coefficient near to one (Figure 2B). 
Figure 2. Different inhibition effects by various GM doses, and the dose-inhibition curve of GM. (A) With GM concentration increasing from 10 to $300 \mu \mathrm{M}$, the blocking effect increased gradually. The BK current was nearly completely blocked in the presence of $300 \mu \mathrm{M}$ GM. The above results were obtained from the same cell at $-50 \mathrm{mV}$; (B) The curve was derived by co-application of $100 \mu \mathrm{M}$ ACh and increasing concentrations of GM. Only peak current values are plotted, expressed as the percentage of the peak control current evoked by ACh alone. Each point is the mean \pm SD of 5 cells.
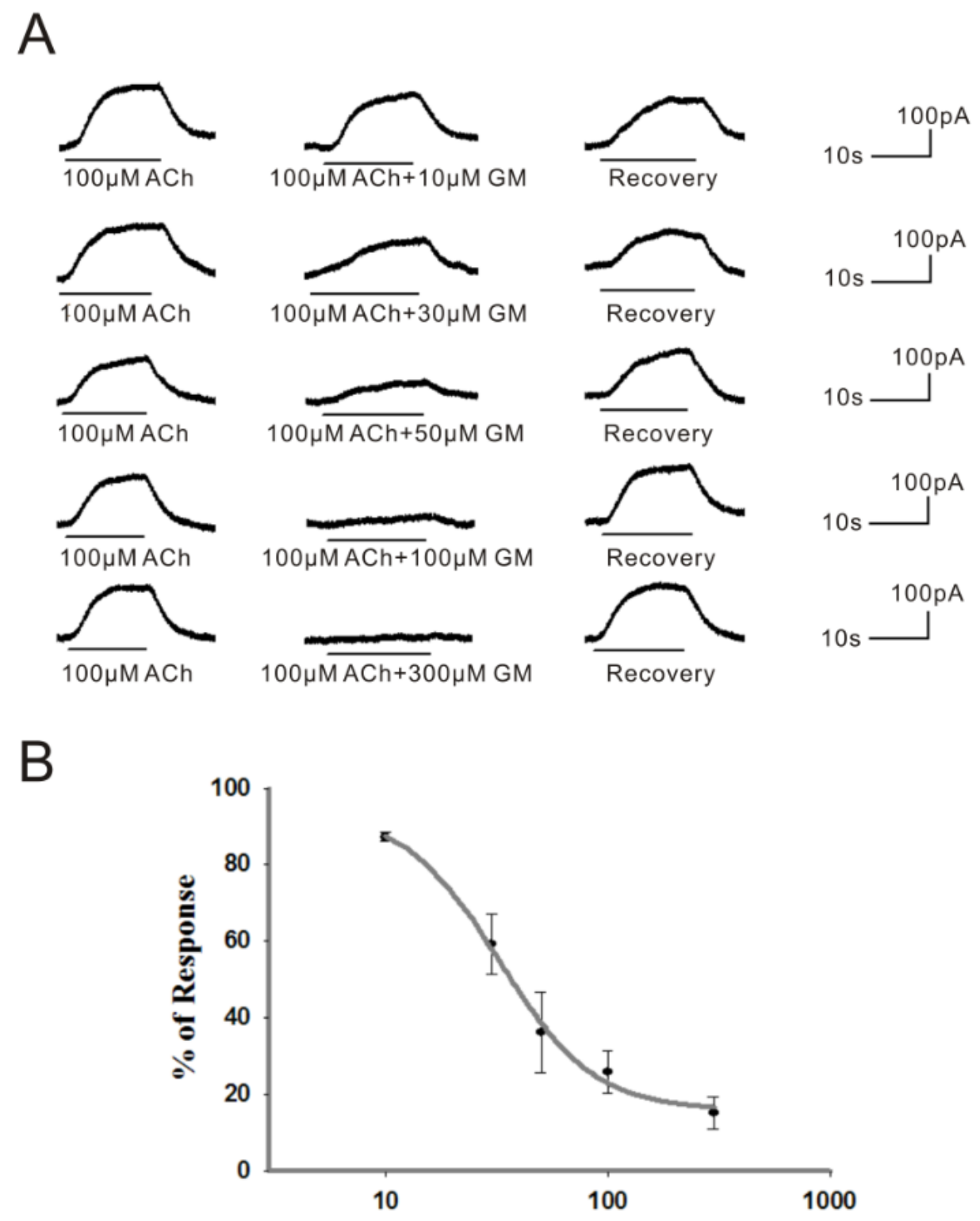

We further studied the I/V relationship of BK currents induced by ACh supplemented with gentamicin. As shown in Figure 3,50 $\mu \mathrm{M}$ GM blocked $100 \mu \mathrm{M}$ ACh-induced BK current by $56.2 \% \pm 9.1 \%(n=5), 54.8 \% \pm 8.9 \%(n=5)$ and $55.8 \% \pm 9.8 \%(n=5)$ at holding potentials of -30 , -50 and $-70 \mathrm{mV}$, respectively. The homogeneity test of variance showed that there was no significant difference among three groups ( $p=0.54$ ). Using the one-way ANOVA, we found that the $F$ value was 0.76 and the $p$ value was 0.62 , which indicated that there was no significant difference among the three groups. Therefore, GM inhibited ACh-induced BK currents in a voltage-independent manner. 
Figure 3. The blocking effects of GM at different holding potential. (A) Currents were sequential current traces evoked by $100 \mu \mathrm{M}$ ACh (ACh100) alone or with $50 \mu \mathrm{M}$ GM at holding potentials of $-30,-50$ and $-70 \mathrm{mV}$. Results were obtained from the same cell; (B) Bar histogram showing the percentage of the blocking effect of $50 \mu \mathrm{M}$ GM on $100 \mu \mathrm{M}$ ACh-induced BK currents at three different holding potentials $(-30,-50$ and $-70 \mathrm{mV})$. Each point is the mean $\pm \mathrm{SD}$ of 5 cells.
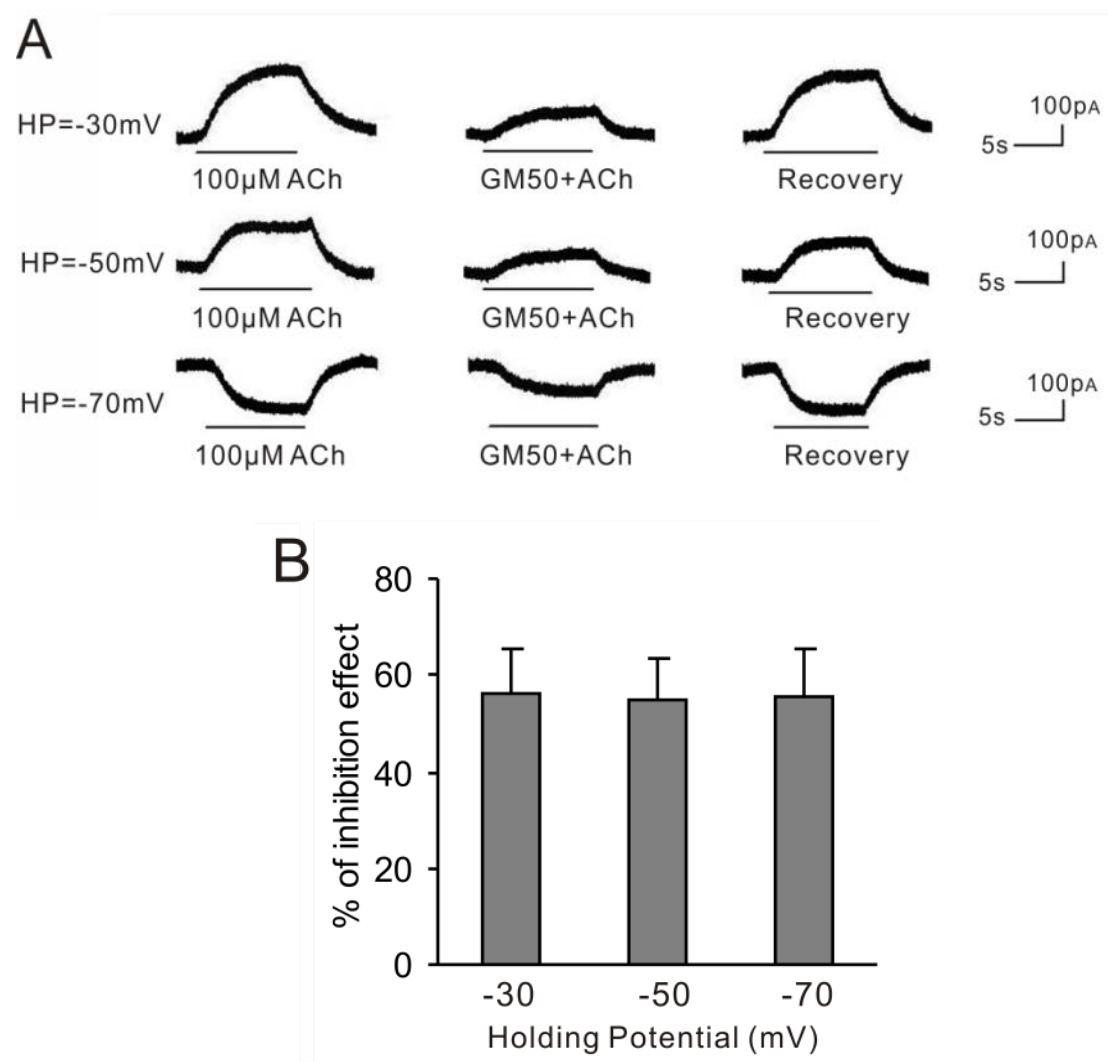

\subsection{Inhibition of GM Is not Affected by ACh Concentration}

To determine whether GM could compete with ACh at its binding sites on the M2 mAChR, we increased the concentration of ACh with a fixed GM concentration. Our previous study demonstrated that the BK current nearly peaked at a concentration of $500 \mu \mathrm{M}$ of ACh [28], indicating that M2 mAChRs of VHCs II were nearly saturated at that concentration. Therefore, in this study we tested three different solutions containing 100, 300 and $500 \mu \mathrm{M}$ ACh with $50 \mu \mathrm{M} \mathrm{GM}$. As shown in Figure 4, in the presence of these three ACh concentrations, $50 \mu \mathrm{M}$ GM blocked the BK current by $55.0 \% \pm 10.7 \%$ $(n=5), 54.0 \% \pm 10.9 \%(n=5)$ and $50.7 \% \pm 13.7 \%(n=5)$, respectively. The homogeneity test of variance showed that there was no significant difference among the three groups $(p=0.34)$. Using the one-way ANOVA, we found that the $F$ value was 0.82 and the $P$ value was 0.48 , which indicated that there was no significant difference among the three groups. Therefore, increasing the ACh concentration did not affect the blocking effect of GM, and the GM inhibition was not due to competition with ACh at the M2 mAChR sites. 
Figure 4. Increasing ACh concentration has little influence on GM inhibition effect. (A) The above currents were sequential current traces evoked by $100 \mu \mathrm{M}$ ACh (ACh100) and different ACh concentrations (100, 300 and $500 \mu \mathrm{M})$ supplemented with $50 \mu \mathrm{M}$ GM. The cell was clamped at $-50 \mathrm{mV}$; (B) Bar histogram shows the percentage of the blocking effect of $50 \mu \mathrm{M}$ GM supplemented with 100,300 and $500 \mu \mathrm{M}$ ACh on the current evoked by $100 \mu \mathrm{M}$ ACh. Each point is the mean \pm SD of 5 cells.

A
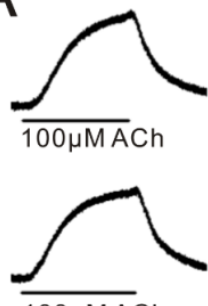

$\overline{100 \mu \mathrm{MACh}}$

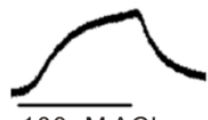

$\overline{100 \mu \mathrm{M} \mathrm{ACh}}$
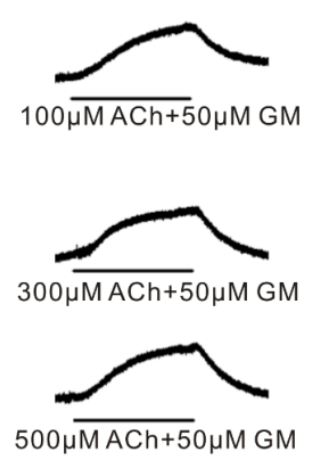
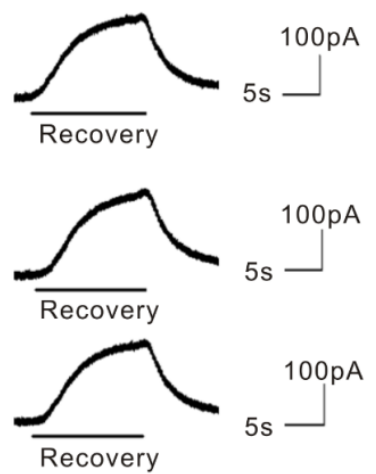

B

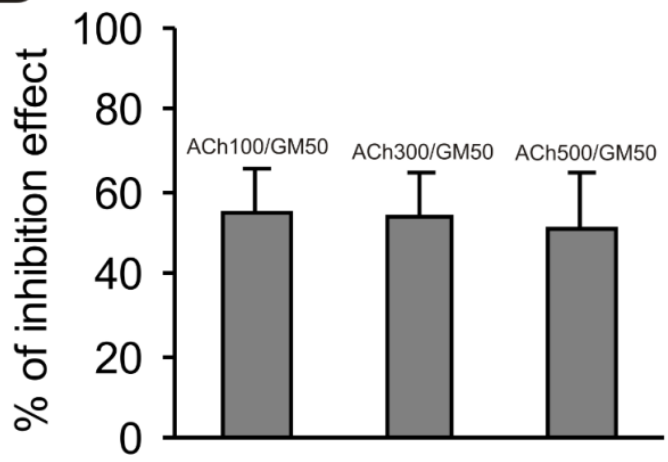

Our previous findings showed that the BK current evoked by $3 \mathrm{mM}$ ACh was approximately 1.5 times of that activated by $100 \mu \mathrm{M}$ ACh in guinea pig VHCs II [28]. Therefore, the M2 mAChRs of VHCs II may not be saturated at $100 \mu \mathrm{M}$ ACh. Under this condition, increasing the ACh concentration above $100 \mu \mathrm{M}$ would reduce the GM blocking effect by activating more M2 mAChRs and triggering more $\mathrm{Ca}^{2+}$ influx to activate more BK channels. However, our results showing that activation of more M2 mAChRs failed to increase $\mathrm{K}^{+}$efflux were not consistent with this hypothesis. Therefore, another mechanism must be responsible for this inhibition.

\subsection{Increasing the Extracellular $\mathrm{Ca}^{2+}$ Concentration Antagonizes GM Inhibition and GM Can Block $\mathrm{Ca}^{2+}$ Evoked by (-)-Bay-K8644}

Since GM competed with $\mathrm{Ca}^{2+}$, we wondered whether the GM-mediated inhibitory effect on ACh-induced BK currents was mainly due to impairment of $\mathrm{Ca}^{2+}$ influx from the L-type $\mathrm{Ca}^{2+}$ channels in guinea pig VHCs II. Therefore, we increased the extracellular calcium concentration $\left(\left[\mathrm{Ca}^{2+}\right]_{\mathrm{o}}\right)$ and then observed the blocking effect.

Our previous study showed that the ACh-induced BK current amplitude increased with the change of $\left[\mathrm{Ca}^{2+}\right]_{\mathrm{o}}$ from 2 to $4 \mathrm{mM}$, and that the current amplitude did not increase at concentrations higher than $4 \mathrm{mM}$ [28]. Therefore, we decided to analyze the blocking effect of GM in 2 and $4 \mathrm{mM}\left[\mathrm{Ca}^{2+}\right]_{\mathrm{o}}$ solutions. As shown in Figure 5A,B, the blocking effect of $50 \mu \mathrm{M}$ GM changed from 58.1\% \pm 9.7\% $(n=6)$ to $40.3 \% \pm 8.4 \%(n=6, p<0.05)$ upon increasing $\left[\mathrm{Ca}^{2+}\right]_{\mathrm{o}}$ from 2 to $4 \mathrm{mM}$. These results showed that GM could block BK currents in both normal and higher $\left[\mathrm{Ca}^{2+}\right]_{\mathrm{o}}$ solutions and the blocking effect was weaker in the elevated $\left[\mathrm{Ca}^{2+}\right]_{0}$ condition. These results indicate that $\mathrm{Ca}^{2+}$ may compete with $\mathrm{GM}$ to antagonize GM inhibitory effect. 
Figure 5. Increasing $\left[\mathrm{Ca}^{2+}\right]_{\mathrm{o}}$ antagonizes the GM inhibition effect of the BK current. (A) The sequential current traces evoked by $100 \mu \mathrm{M}$ ACh alone or with $50 \mu \mathrm{M}$ GM (ACh100/GM50) in the standard $\left(\left[\mathrm{Ca}^{2+}\right]_{\mathrm{o}}=2 \mathrm{mM}\right)$ or $4 \mathrm{mM}\left[\mathrm{Ca}^{2+}\right]_{\mathrm{o}}$ extracellular solution. The above currents were obtained from the same VHC II at $-50 \mathrm{mV}$; (B) Bar histogram shows the percentage of inhibition effect of $50 \mu \mathrm{M}$ GM on the BK current evoked by $100 \mu \mathrm{M}$ ACh in standard extracellular solution or $4 \mathrm{mM}\left[\mathrm{Ca}^{2+}\right]_{\mathrm{o}}$ solution. Each point is the mean $\pm \mathrm{SD}$ of 6 cells.

A
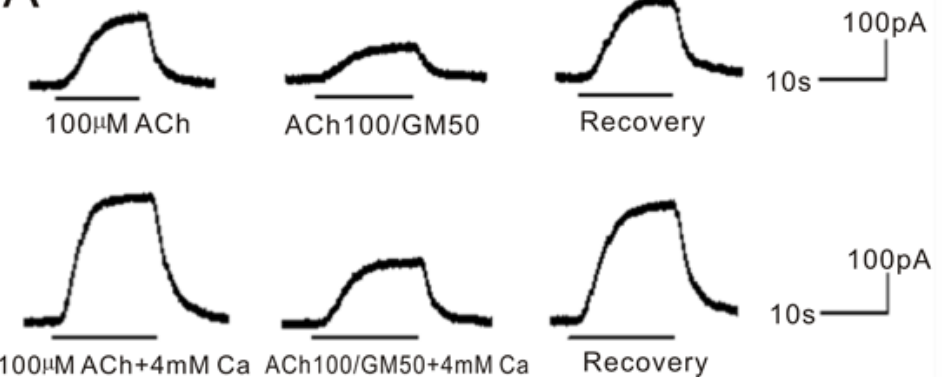

B

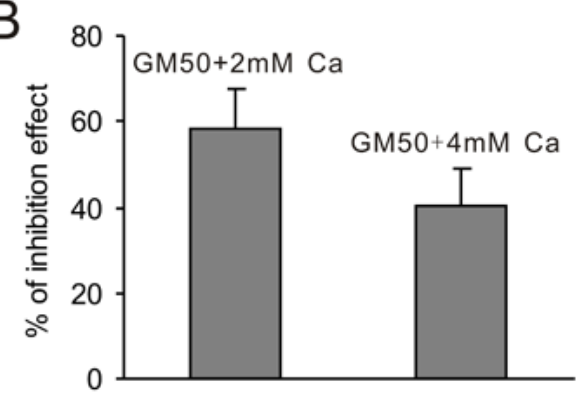

It is known that nAChRs have high permeability to $\mathrm{Ca}^{2+}$ and can activate small-conductance $\mathrm{Ca}^{2+}$-dependent $\mathrm{K}^{+}$channels in guinea pig VHCs II. Although our previous findings showed that the nAChRs were not involved in the BK currents recorded [27], it was still possible that $\mathrm{Ca}^{2+}$ influx though nAChRs was greater with higher $\left[\mathrm{Ca}^{2+}\right]_{0}$. As shown in Figure $6,1 \mu \mathrm{M}$ strychnine, which is a potent $\mathrm{nAChR}$ antagonist, did not affect the BK current under normal $\left[\mathrm{Ca}^{2+}\right]_{\mathrm{o}} .(n=5, p=0.46)$ or $4 \mathrm{mM}\left[\mathrm{Ca}^{2+}\right]_{\mathrm{o}}$. ( $n=5, p=0.37$ ) solutions. These data indicated that there was no $\mathrm{Ca}^{2+}$ influx through $\mathrm{nAChRs}$ even in high $\left[\mathrm{Ca}^{2+}\right]_{0}$ solution. The nAChR, which is not involved in BK currents, only affected the antagonism of elevated calcium concentrations by increasing $\mathrm{Ca}^{2+}$ influx. Therefore, we could rule out the involvement of nAChRs in the antagonism of GM blocking effect under elevated $\left[\mathrm{Ca}^{2+}\right]_{\mathrm{o}}$ conditions.

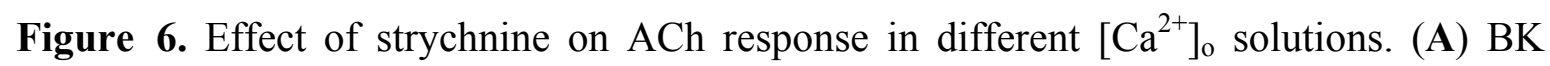
currents evoked by $100 \mu \mathrm{M}$ ACh were insensitive to $1 \mu \mathrm{M}$ strychinine in both standard extracellular solution $\left(\left[\mathrm{Ca}^{2+}\right]_{\mathrm{o}}=2 \mathrm{mM}\right)$ and $4 \mathrm{mM}\left[\mathrm{Ca}^{2+}\right]_{\mathrm{o}}$ solution. These currents were obtained from the same VHC II at $-50 \mathrm{mV}$; (B) A bar histogram shows the percentage of blocking effect of $1 \mu \mathrm{M}$ strychnine on the BK current evoked by $100 \mu \mathrm{M}$ ACh in standard extracellular solution or $4 \mathrm{mM}$ solution. Each point is the mean $\pm \mathrm{SD}$ of 5 cells.

A
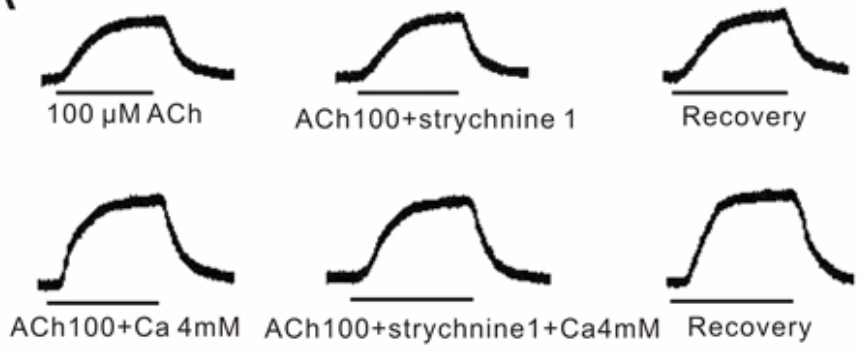

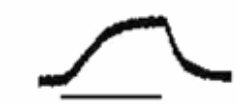

ACh $\overline{100+\text { strychnine } 1}$
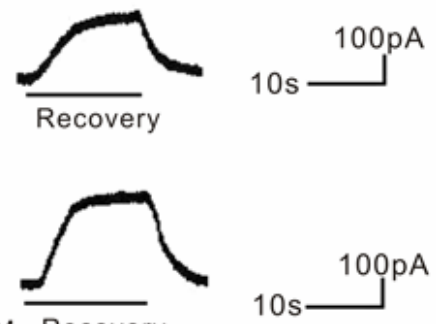

B

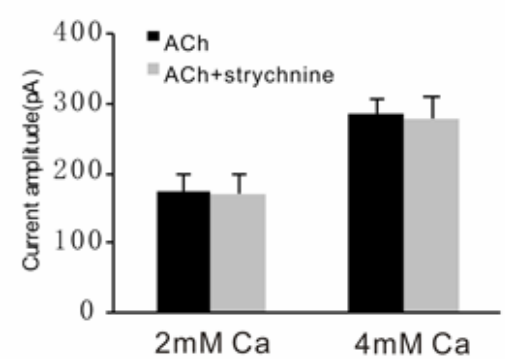

The above data indicated that GM blocked BK currents by impairing $\mathrm{Ca}^{2+}$ influx, which was not mediated by $n$ AChRs. Our previous studies have reported that ACh evoked BK currents by triggering $\mathrm{Ca}^{2+}$ influx through L-type $\mathrm{Ca}^{2+}$ channels [27]. Therefore, GM likely decreased $\mathrm{Ca}^{2+}$ influx through 
L-type $\mathrm{Ca}^{2+}$ channels. To study the direct effect of GM on L-type $\mathrm{Ca}^{2+}$ channels, we assessed whether GM affected the calcium current evoked by (-)-Bay-K8644 (the L-type $\mathrm{Ca}^{2+}$ channel agonist). We first verified the (-)-Bay-K8644-activated inward current by applying nifedipine (a $\mathrm{Ca}^{2+}$ channel blocker). As shown in Figure 7, the currents evoked by $10 \mu \mathrm{M}(-)$-Bay-K8644 in guinea pig VHCs II was potently reduced by $10 \mu \mathrm{M}$ nifedipine to $25.1 \% \pm 9.8 \%(n=5)$ as expected. The results showed that the (-)-Bay-K8644-activated $\mathrm{Ca}^{2+}$ current was blocked by $50 \mu \mathrm{M} \mathrm{GM}(48.4 \pm 10.1$ vs. $23.2 \pm 11.2 \mathrm{pA}$, $p<0.05, n=5$; Figure 7) and $300 \mu \mathrm{M} \mathrm{GM}(50.4 \pm 9.8 v s .17 .0 \pm 11.5 \mathrm{pA}, p<0.05, n=5$; Figure 7) compared to control, respectively. These results indicated that GM decreased the influx of $\mathrm{Ca}^{2+}$ through the L-type $\mathrm{Ca}^{2+}$ channel.

Figure 7. Effect of GM on (-)-Bay-K8644-activated current $(\mathrm{HP}=-50 \mathrm{mV})$. (A) The (-)-Bay-K8644-activated current was strongly blocked by $10 \mu \mathrm{M}$ nifedipine. In addition, both 50 and $300 \mu \mathrm{M}$ GM could block the current induced by $10 \mu \mathrm{M}$ (-)-Bay-K8644; (B) Bar histogram showed the effects of $10 \mu \mathrm{M}$ nifedipine, $50 \mu \mathrm{M} \mathrm{GM}$, and $300 \mu \mathrm{M} \mathrm{GM}$ on the currents evoked by $10 \mu \mathrm{M}(-)$-Bay-K8644. Each point represents the mean $\pm \mathrm{SD}$ of 5 cells.
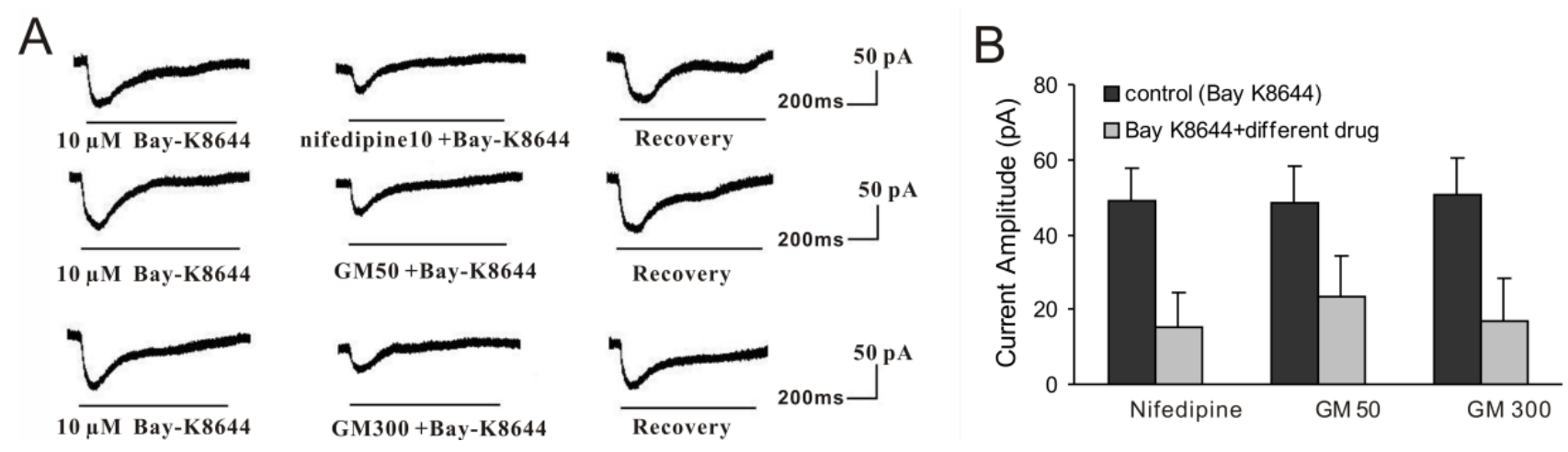

2.4. BK Current Evoked by NS1619 Insensitive to $50 \mu M$ GM and Only Slightly Blocked by $300 \mu M$ GM

In order to determine whether GM has a direct blocking effect on BK channels in guinea pig VHCs II, we observed the effect of GM on BK currents activated by NS1619 (a BK channel activator). We verified the NS1619-activated outward current by applying IBTX (a BK channel blocker). As expected, the BK current induced by $30 \mu \mathrm{M}$ NS1619 was potently blocked by $200 \mathrm{nM}$ IBTX to $19.1 \% \pm 7.8 \%$ $(n=5)$ (Figure 8$)$. Therefore, the current activated by NS1619 was the BK current. We also found that the NS1619-activated BK current was not sensitive to $50 \mu \mathrm{M}$ GM (control $113 \pm 16.7 \mathrm{pA}, 50 \mu \mathrm{M} \mathrm{GM}+$ NS1619 $109.5 \pm 22.2 \mathrm{pA}, p=0.26, n=5$; Figure 8). Moreover, $300 \mu \mathrm{M}$ GM could only slightly block the current (control 115.2 $\pm 19.8 \mathrm{pA}, 300 \mu \mathrm{M}$ GM $+\mathrm{NS} 161987.4 \pm 15 \mathrm{pA}, p=0.03, n=5$; Figure 8). These results indicate that GM may have a slight direct blocking effect on the BK channel at high concentrations. 
Figure 8. Effect of GM on NS1619-activated current (HP $=-50 \mathrm{mV})$. (A) The NS1619-activated current was strongly blocked by $200 \mathrm{nM}$ IBTX. In addition, $50 \mu \mathrm{M}$ GM could not block the current induced by $30 \mu \mathrm{M}$ NS1619, while $300 \mu \mathrm{M}$ inhibited it slightly; (B) Bar histogram showed the effects of $200 \mathrm{nM}$ IBTX, $50 \mu \mathrm{M}$ GM, and $300 \mu \mathrm{M}$ GM on the current evoked by $30 \mu \mathrm{M}$ NS1619. Each point represents the mean \pm SD of 5 cells.

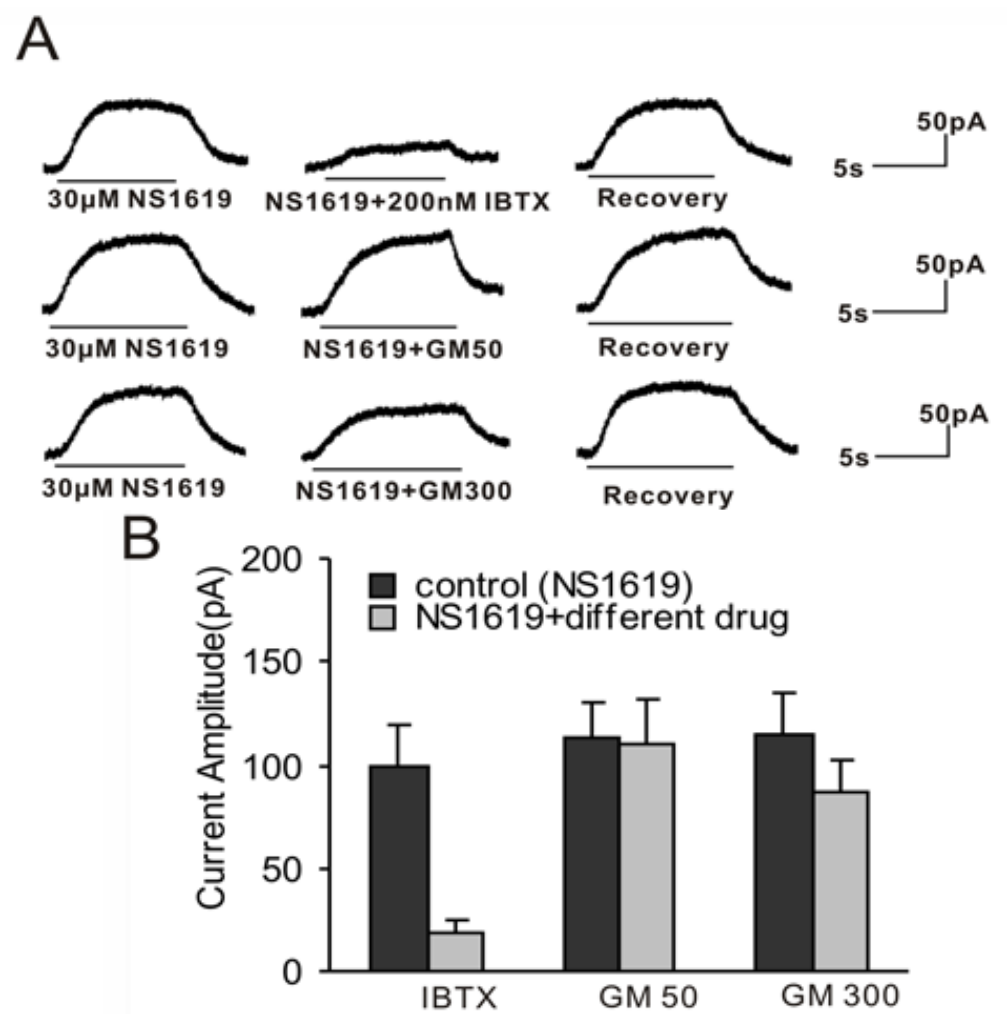

\section{Discussion}

It has been reported that GM can damage efferent nerve endings on VHCs [30,31], but the physiological mechanism of this damage is still unclear. In the present study, using the whole-cell patch clamp technique, we demonstrated that GM could reversibly block the ACh-induced BK current in guinea pig VHCs II in a dose-dependent and voltage-independent manner, which indicated that acute GM application could inhibit the vestibular efferent system at the level of the postsynaptic membrane in mammalian VHCs.

Our previous studies demonstrated that the BK channel and the L-type calcium channel were co-located in guinea pig VHCs II [29]. ACh could evoke the BK current by triggering the $\mathrm{Ca}^{2+}$ influx from L-type calcium channels in guinea pig VHCs II mediated by M2 mAChRs [27]. Since GM could block the ACh-induced BK current in isolated VHCs II, it would affect at least one site of the signal transduction pathway. The acute application of GM in this study likely inhibited receptors or ion channels present on the plasma membrane of cells. As shown in Figure 9 [27], in the signal transduction pathway of the ACh-induced BK current, there were only three possible blocking sites on the membrane: the M2 mAChR, the L-type $\mathrm{Ca}^{2+}$ channel, and the BK channel. 
Figure 9. The L-type calcium channel was the probable blocking site of GM. The signal transduction pathway of the ACh-induced BK current in guinea pig VHCs II and the probable blocking site of GM on the pathway. GM probably blocks the ACh-induced BK current mainly by competing with $\mathrm{Ca}^{2+}$ at the L-type calcium channel. +: excitation.

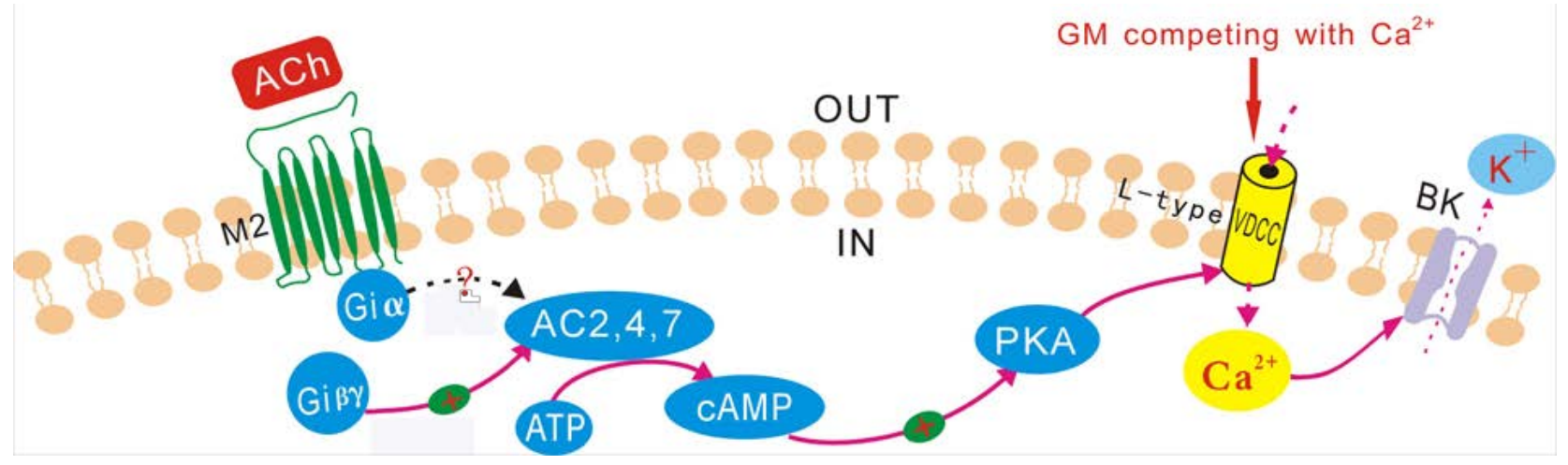

First, if GM could compete with ACh at the M2 mAChR, increasing ACh concentration would reduce the GM inhibitory effect of BK currents. It was previously reported that M2 mAChRs of VHCs II were not saturated at $100 \mu \mathrm{M}$ ACh [28], therefore, increasing the ACh concentration to 300 and $500 \mu \mathrm{M}$ would activate more M2 mAChRs. However, the present study showed that increased M2 mAChR activation did not lead to reduction of GM inhibition, which eliminated the hypothesis of direct competition of GM with ACh at the M2 mAChR. Therefore, GM may block BK currents by affecting calcium influx or directly blocking BK channels.

The current findings demonstrated that increasing $\left[\mathrm{Ca}^{2+}\right]_{0}$ could antagonize GM blocking effect, which indicated that GM may block the BK current by impairing calcium influx. It has been reported that GM could impair the calcium influx from the calcium channels $[6,31,32]$ and the specific binding sites at the nAChRs [14]. In guinea pig VHCs II, nAChRs and calcium channels coexist, so increasing the extracellular $\mathrm{Ca}^{2+}$ concentration alleviated GM blocking effect through both or only one of them. Our previous findings showed the nAChRs were not involved in the activation of BK channels and BK currents evoked by ACh was insensitive to strychnine [27]. The present results showed that the ACh-induced BK currents were not affected by strychnine even in the higher $\left[\mathrm{Ca}^{2+}\right]_{\mathrm{o}}$ solution. Recently, we verified that $n A C h R s$ were deactivated in collagenase IA-isolated VHCs II [33]. Therefore, the effect of elevated $\left[\mathrm{Ca}^{2+}\right]_{0}$ on the GM blocking effect was not due to nAChRs, but rather the L-type $\mathrm{Ca}^{2+}$ channel. To obtain more direct evidence of GM competing with $\mathrm{Ca}^{2+}$, we recorded the $\mathrm{Ca}^{2+}$ current evoked by (-)-Bay-K8644 and observed the direct effect of GM on it. The results showed that both 50 and $300 \mu \mathrm{M}$ of $\mathrm{GM}$ potently inhibited the $\mathrm{Ca}^{2+}$ currents, indicating that GM could block L-type $\mathrm{Ca}^{2+}$ channels and decrease the influx of $\mathrm{Ca}^{2+}$. GM slightly blocked NS1619-activated BK currents at a high concentration of $300 \mu \mathrm{M}$, so the BK channel might be the blocking target of GM. Some studies have also shown that aminoglycosides could directly block the $\mathrm{K}^{+}$channel [34-37]; however, the BK channel would not be the main blocking site. One reason was because the $\mathrm{IC}_{50}$ of GM to the ACh-induced BK current was $36.1 \pm 7.8 \mu \mathrm{M}$, but $50 \mu \mathrm{M}$ GM did not block the NS1619-activated BK current and only very slightly inhibited it at a concentration of $300 \mu \mathrm{M}$. The other important reason was that it could not explain the reduction of GM blocking effect with increasing $\left[\mathrm{Ca}^{2+}\right]_{\mathrm{o}}$. Therefore, the direct blocking of BK channels might be a very small explanation, but is not the major mechanism. 
Our previous study demonstrated that the activation of ACh-induced BK current was mainly dependent on external $\mathrm{Ca}^{2+}$ influx through L-type calcium channels, but not the release of intracellular $\mathrm{Ca}^{2+}$ stores [28]. Based on the above results, the GM blocking effect was likely due to competing with $\mathrm{Ca}^{2+}$ at the L-type calcium channel, which impaired the calcium influx to diminish the BK current. This provided a good explanation for the absence of increased $\mathrm{K}^{+}$efflux even after the activation of more M2 mAChRs. Martini et al. [20] have reported that GM also blocked the $\mathrm{Ca}^{2+}$-dependent $\mathrm{K}^{+}$current by impairing the $\mathrm{Ca}^{2+}$ influx in semicircular canal hair cells of the frog.

Our results also showed that GM reversibly blocked the ACh-induced BK current in guinea pig VHCs II in the micromolar range. GM also blocked the ACh-induced small-conductance calcium-dependent potassium current in guinea pig outer hair cells [14]. However, the $\mathrm{IC}_{50}(36.3 \mu \mathrm{M})$ of GM to the ACh-induced BK current mediated by the M2 mAChR was higher than GM $(5.5 \mu \mathrm{M})$ to ACh-evoked $\mathrm{K}^{+}$currents in outer hair cells at the $\mathrm{nAChR}$. This may be due to differences in cell type or cholinergic receptor type.

\section{Methods}

\subsection{Ethics Statement}

The Institutional Animal Care and Use Committee of Tong-ji Medical College approved this animal experiment on 1 June 2010 (IACUC Number: 289).

\subsection{Animal Procedures and VHCs II Preparation}

Collagenase type IA-dissociated vestibular hair cells were isolated as previously described [27-29]. First, young guinea pigs (weighing 250-300 g, 6-10 weeks-old) were deeply anesthetized by intramuscular injection of $0.3 \mathrm{~mL}$ of a mix of $1 / 3$ xylazine (2\%, Rompum, Bayer, Leverkusen, Germany) and $2 / 3$ ketamine hydrochlorate (50 mg/mL, Ketalar, Parke-Davis, L'Arche, France), and decapitated. Then we removed vestibular epithelium (three semicircular canals and two otolithic organs) and incubated it for $5 \mathrm{~min}$ at room temperature $\left(20-24^{\circ} \mathrm{C}\right)$ with $0.2 \mathrm{mg} / \mathrm{mL}$ collagenase IA in a low $\mathrm{Ca}^{2+}$ and $\mathrm{Mg}^{2+}$-free balanced salt solution $\left(137 \mathrm{mM} \mathrm{NaCl}, 5.4 \mathrm{mM} \mathrm{KCl}, 0.1 \mathrm{mM} \mathrm{CaCl}_{2}, 0.2 \mathrm{mM} \mathrm{Na} \mathrm{HPO}_{4}, 0.4 \mathrm{mM}\right.$ $\mathrm{KH}_{2} \mathrm{PO}_{4}, 10 \mathrm{mM}$ glucose ( $\mathrm{pH}$ 7.2)). Next, the low calcium solution was replaced with normal external solution containing $2 \mathrm{mM} \mathrm{CaCl}_{2}$ to stop the enzymatic action. VHCs were isolated by mechanical dissociation and placed on the bottom of the experimental chamber, which was coated with rat collagen. We identified VHCs II by the cylindrical shape and absence of a distinct neck region [38].

\subsection{Electrophysiology}

The ACh-induced BK currents were recorded in the whole-cell configuration, using an Axon-200B patch clamp amplifier (Axon Instruments, Foster City, CA, USA). Patch electrodes were fabricated from thick-walked borosilicate glass capillaries, using a Model P-97 electrode puller (Sutter Instrument Company, Novato, CA, USA). Electroderesistances were maintained between 3 and $6 \mathrm{M} \Omega$ when filled with the internal solution, as described below. Records were low-pass filtered at $5 \mathrm{kHz}$ with a four-pole Bessel filter. After gigaseal formation onto the basolateral membrane of VHCs and membrane 
disruption, the membrane capacitance was $4.8 \pm 1.7 \mathrm{pF}$ on average $(\mathrm{Cm}, n=6)$ and the series resistance (RS, 6-15 M $\Omega$ ) was compensated by up to $80 \%$. The drug was administered to a patched cell at a holding potential of $-50 \mathrm{mV}$.

The components of the external solution were as follows: $150 \mathrm{mM} \mathrm{NaCl}, 5 \mathrm{mM} \mathrm{KCl}, 2 \mathrm{mM} \mathrm{CaCl}_{2}$, $1 \mathrm{mM} \mathrm{MgCl}_{2}, 5 \mathrm{mM}$ glucose, and $10 \mathrm{mM}$ HEPES ( $\mathrm{pH}$ 7.2). The components of the internal solution were as follows: $150 \mathrm{mM} \mathrm{KCl}, 2 \mathrm{mM} \mathrm{MgCl}$, $3 \mathrm{mM} \mathrm{Na}_{2} \mathrm{ATP}, 0.1 \mathrm{mM}$ EDTA and $10 \mathrm{mM}$ HEPES ( $\mathrm{pH}$ 7.2). The $\mathrm{KCl}$ was replaced by $\mathrm{CsCl}$ when the calcium current was recorded.

\subsection{Drug Application}

All drugs were purchased from Sigma (St. Louis, MO, USA). ACh, gentamicin (GM), methoctramine (an M2 selective AChR antagonist), strychnine (a selective $n$ AChR inhibitor), and iberiotoxin (IBTX, a selective BK channel blocker) were directly dissolved in the external solution. NS1619 (a BK channel activator) was formulated as a $10 \mathrm{mM}$ stock solution in DMSO (Sigma, St. Louis, MO, USA). (-)-Bay-K8644 (the L-type calcium channel agonist) and nifedipine (a calcium channel blocker) were formulated as $10 \mathrm{mM}$ stock solutions in DMSO and diluted for use. The test solutions were dissolved daily before use and applied to cells by a gravity-delivered linear barrel microperfusion system as previously described [27-29]. The microperfusion system was composed of a series of fused silica tubes (eight tubes; outer diameter, $500 \mu \mathrm{m}$; internal diameter, $200 \mu \mathrm{m}$ ) connected to a series of independent reservoirs. The tip of the tube was placed approximately 100 to $150 \mu \mathrm{m}$ from the cells. This microperfusion system was manipulated by shifting the tubes horizontally with a Leitz micromanipulator (ACS01, Leitz Corp., Wetzlar, Germany).

\subsection{Data Analysis}

Data were analyzed and plotted by using the pCLAMP8.1 Clampfit 8.1 software (Axon Instruments, Foster City, CA, USA) and SigmaPlot 9.0 (Systat Software, Richmond, CA, USA). Results were presented as the mean $\pm \mathrm{SD}$. Statistical significance was determined using the Student's $t$ test to compare the means between two groups, and one-way analysis of variance (ANOVA) to compare the means among more than two groups. Differences were considered to be significant if $p<0.05$; all the differences listed were statistically significant, unless stated otherwise.

\section{Conclusions}

In conclusion, our findings indicate that acute GM application could block the ACh-induced BK current in guinea pig VHCs II by competing with $\mathrm{Ca}^{2+}$ at the L-type calcium channel, which results in the decrease of $\mathrm{Ca}^{2+}$ influx and the subsequent reduction of the BK current. Thus, the effect of GM on $n$ AChRs in guinea pig VHCs II should be further investigated.

\section{Acknowledgments}

This study was funded by the Major State Basic Research Development Program of China (973 program) (No. 2011CB504504), the National Science and Technology Pillar Program during the 
Twelfth Five-year Plan Period (No. 2012BAI12B02) and the National Nature Science Foundation of China (No. 30872865, No. 81230021 and No. 81371095).

\section{Conflicts of Interest}

The authors declare no conflict of interest.

\section{References}

1. Webster, J.C.; McGee, T.M.; Carroll, R.; Benitez, J.T.; Williams, M.L. Ototoxicity of gentamicin. Histopathologic and functional results in the cat. Trans. Am. Acad. Ophthalmol. Otolaryngol. 1970, $74,1155-1165$.

2. Blakley, B.W. Update on intratympanic gentamicin for Ménière's disease. Laryngoscope 2000, 110, 236-240.

3. Straube, A. Pharmacology of vertigo/nystagmus/oscillopsia. Curr. Opin. Neurol. 2005, 18, 11-14.

4. Dobrev, D.; Ravens, U. Therapeutically relevant concentrations of neomycin selectively inhibit P-type $\mathrm{Ca}^{2+}$ channels in rat striatum. Eur. J. Pharmacol. 2003, 461, 105-111.

5. Fiekers, J.F. Effects of the aminoglycoside antibiotics, streptomycin and neomycin, on neuromuscular transmission. II. Postsynaptic considerations. J. Pharmacol. Exp. Ther. 1983, 225, 496-502.

6. Parsons, T.D.; Obaid, A.L.; Salzberg, B.M. Aminoglycoside antibiotics block voltage-dependent calcium channels in intact vertebrate nerve terminals. J. Gen. Physiol. 1992, 99, 491-504.

7. Pichler, M.; Wang, Z.; Grabner-Weiss, C.; Reimer, D.; Hering, S.; Grabner, M.; Glossmann, H.; Striessnig, J. Block of $\mathrm{P} / \mathrm{Q}$-type calcium channels by therapeutic concentrations of aminoglycoside antibiotics. Biochemistry 1996, 35, 14659-14664.

8. Kroese, A.B.; Das, A.; Hudspeth, A.J. Blockage of the transduction channels of hair cells in the bullfrog's sacculus by aminoglycoside antibiotics. Hear Res. 1989, 37, 203-217.

9. Marcotti, W.; Netten, S.M.V.; Kros, C.J. The aminoglycoside antibiotic dihydrostreptomycin rapidly enters mouse outer hair cells through the mechano-electrical transducer channels. J. Physiol. 2005, 567, 505-521.

10. Ohmori, H. Mechano-electrical transduction currents in isolated vestibular hair cells of the chick. J. Physiol. 1985, 359, 189-217.

11. Wackym, P.A.; Chen, C.T.; Ishiyama, A.; Pettis, R.M.; López, I.A.; Hoffman, L. Muscarinic acetylcholine receptor subtype mRNAs in the human and rat vestibular periphery. Cell Biol. Int. 1996, 20, 187-192.

12. Winegar, B.D.; Haws, C.M.; Lansman, J.B. Subconductance block of single mechanosensitive ion channels in skeletal muscle fibers by aminoglycoside antibiotics. J. Gen. Physiol. 1996, 107, 433-443.

13. Amici, M.; Eusebi, F.; Miledi, R. Effects of the antibiotic gentamicin on nicotinic acetylcholine receptors. Neuropharmacology 2005, 49, 627-637.

14. Blanchet, C.; Erostequi, C.; Suqasawa, M.; Dulon, D. Gentamicin blocks ACh-evoked $\mathrm{K}^{+}$current in guinea-pig outer hair cells by impairing $\mathrm{Ca}^{2+}$ entry at the cholinergic receptor. J. Physiol. 2000, 525, 641-654. 
15. Rothlin, C.V.; Katz, E.; Verbotsky, M.; Vetter, D.E.; Heinemann, S.F.; Elqoyhen, A.B. Block of the alpha9 nicotinic receptor by ototoxic aminoglycosides. Neuropharmacology 2000, 39, 2525-2532.

16. Smith, D.W.; Erre, J.P.; Aran, J.M. Rapid, reversible elimination of medial olivocochlear efferent function following single injections of gentamicin in the guinea pig. Brain Res. 1994, 652, 243-248.

17. Yoshida, N.; Liberman, M.C.; Brown, M.C.; Sewell, W.F. Gentamicin blocks both fast and slow effects of olivocochlear activation in anesthetized guinea pigs. J. Neurophysiol. 1999, 82, 3168-3174.

18. Mulders, W.H.; Robertson, D. Gentamicin abolishes all cochlear effects of electrical stimulation of the inferior colliculus. Exp. Brain Res. 2006, 174, 35-44.

19. Avan, P.; Erre, J.P.; da Costa, D.L.; Aran, J.M.; Popelár, J. The efferent-mediated suppression of otoacoustic emissions in awake guinea pigs and its reversible blockage by gentamicin. Exp. Brain Res. 1996, 109, 9-16.

20. Martini, M.; Canella, R.; Priqioni, I.; Russo, G.; Tavazzani, E.; Fesce, R.; Rossi, M.L. Acute effects of gentamicin on the ionic currents of semicircular canal hair cells in the frog. Hear Res. 2011, 282, 151-160.

21. Guth, P.S.; Perin, P.; Norris, C.H.; Valli, P. The vestibular hair cells: Post-transductional signal processing. Prog. Neurobiol. 1998, 54, 193-247.

22. Ishiyama, A.; Lopez, I.; Wackym, P.A. Molecular characterization of muscarinic receptors in the human vestibular periphery. Implications for pharmacotherapy. Am. J. Otol. 1997, 18, 648-654.

23. Yao, Q.; Cheng, H.; Guo, C.; Zhou, T.; Huang, X.; Kong, W. Muscarinic acetylcholine receptor subtype expression in type II vestibular hair cells of guinea pigs. J. Huazhong Uni. Sci. Technol. 2011, 31, 682-686.

24. Anderson, A.D.; Troyanovskaya, M.; Wackym, P.A. Differential expression of alpha2-7, alpha9 and beta2-4 nicotinic acetylcholine receptor subunit mRNA in the vestibular end-organs and Scarpa's ganglia of the rat. Brain Res. 1997, 778, 409-413.

25. Elgoyhen, A.B.; Vetter, D.E.; Katz, E.; Rothlin, C.V.; Heinemann, S.F.; Boulter, J. alpha10: A determinant of nicotinic cholinergic receptor function in mammalian vestibular and cochlear mechanosensory hair cells. Proc. Natl. Acad. Sci. USA 2001, 98, 3501-3506.

26. Simmons, D.D.; Morley, B.J. Spatial and temporal expression patterns of nicotinic acetylcholine alpha9 and alpha10 subunits in the embryonic and early postnatal inner ear. Neuroscience 2011, 194, 326-336.

27. Guo, C.K.; Wang, Y.; Zhou, T.; Yu, H.; Zhang, W.J.; Kong, W.J. M2 muscarinic ACh receptors sensitive BK channels mediate cholinergic inhibition of type II vestibular hair cells. Hear Res. 2012, 285, 13-19.

28. Kong, W.J.; Guo, C.K.; Zhang, S.; Hao, J.; Wang, Y.J.; Li, Z.W. The properties of ACh-induced BK currents in guinea pig type II vestibular hair cells. Hear Res. 2005, 209, 1-9.

29. Kong, W.J.; Guo, C.K.; Zhang, X.W.; Chen, X.; Zhang, S.; Li, G.Q.; Li, Z.W.; van Cauwenberqe, P. The coupling of acetylcholine-induced BK channel and calcium channel in guinea pig saccular type II vestibular hair cells. Brain Res. 2007, 1129, 110-115. 
30. Wanamaker, H.H.; Gruenwald, L.; Damm, K.J.; Oqata, Y.; Slepecky, N. Dose-related vestibular and cochlear effects of transtympanic gentamicin. Am. J. Otol. 1998, 19, 170-179.

31. Dulon, D.; Zajic, G.; Aran, J.M.; Schacht, J. Aminoglycoside antibiotics impair calcium entry but not viability and motility in isolated cochlear outer hair cells. J. Neurosci. Res. 1989, 24, 338-346.

32. Tan, C.T.; Lee, S.Y.; Yao, C.J.; Liu, S.H.; Lin-Shiau, S.Y. Effects of gentamicin and pH on $\left[\mathrm{Ca}^{2+}\right]_{\mathrm{i}}$ in apical and basal outer hair cells from guinea pigs. Hear Res. 2001, 154, 81-87.

33. Zhou, T.; Wang, Y.; Guo, C.K.; Zhang, W.J.; Yu, H.; Zhang, K.; Kong, W.J. Two distinct channels mediated by $\mathrm{m} 2 \mathrm{mAChR}$ and $\alpha 9 \mathrm{nAChR}$ co-exist in type II vestibular hair cells of guinea pig. Int. J. Mol. Sci. 2013, 14, 8818-8831.

34. Liu, S.Q.; Kaczmarek, L.K. Aminoglycosides block the Kv3.1 potassium channel and reduce the ability of inferior colliculus neurons to fire at high frequencies. J. Neurobiol. 2005, 62, 439-452.

35. Nomura, K.; Naruse, K.; Watanabe, K.; Sokabe, M. Aminoglycoside blockade of Ca ${ }^{2+}$-activated K channel from rat brain synaptosomal membranes incorporated into planar bilayers. J. Membr. Biol. 1990, 115, 241-251.

36. Scott, E.M.; Johnson, M.; Meredith, F.L.; Rennie, K.J. Inhibition of $\mathrm{K}^{+}$Currents in Type I Vestibular Hair Cells by Gentamicin and Neomycin. Audiol. Neurotol. 2013, 18, 317-326.

37. Scarfone, E.; Ulfendahl,M.; Löfstrand, P.; Flock, A. Light- and electron microscopy of isolated vestibular hair cells from the guinea pig. Cell Tissue Res. 1991, 266, 51-58.

38. Lopez, I.; Ayala, C.; Honrubia, V. Synaptophysin immunohistochemistry during vestibular hair cell recovery after gentamicin treatment. Audiol. Neurootol. 2003, 8, 80-90.

(C) 2014 by the authors; licensee MDPI, Basel, Switzerland. This article is an open access article distributed under the terms and conditions of the Creative Commons Attribution license (http://creativecommons.org/licenses/by/3.0/). 